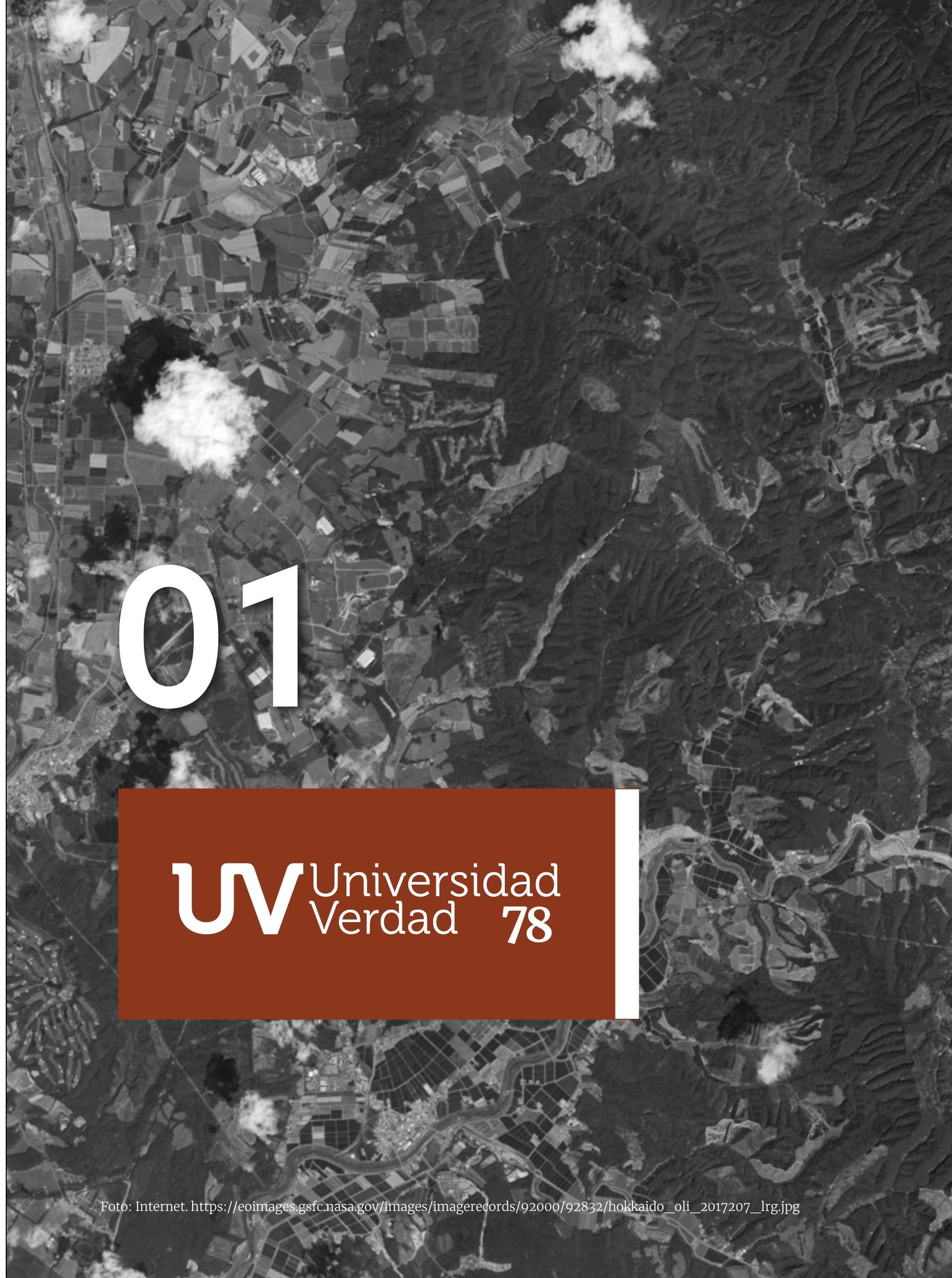




\title{
CAMBIO DE COBERTURA DE SUELO EN LA AMAZONÍA NORTE DEL ECUADOR: UN ANÁLISIS A TRAVÉS DE IMÁGENES SATELITALES NOCTURNAS VIIRS E IMÁGENES LANDSAT
}

\section{Land cover change in the northern Amazon of Ecuador: An analysis through night satellite images VIIRS and LANDSAT images}

\author{
iD Verónica Mejía, Grupo de Estudio sobre Energía, Territorio y Sociedad, Departamento de Geografía, \\ Universitat Autònoma de Barcelona (España) (veromejiaj@gmail.com) \\ (https://orcid.org/0000-0002-9361-8728)
}
(iD Diana Orellana, Departamento Desarrollo, Ambiente y Territorio, Facultad Latinoamericana de Ciencias Sociales - FLACSO (Ecuador) (daorellanafl@flacso.edu.ec)
(https://orcid.org/0000-0002-4684-6613)

iD Pablo Cabrera-Barona, Departamento de Asuntos Públicos, Facultad Latinoamericana de Ciencias Sociales - FLACSO (Ecuador) (pfcabrera@flacso.edu.ec) (https://orcid.org/0000-0002-6225-5717)

\section{Resumen}

En estos últimos años las presiones sobre el territorio y los pueblos amazónicos se han vuelto cada vez más visibles debido a las transformaciones del suelo y las dinámicas territoriales sobre estas zonas antes consideradas remotas y en las que habitan pueblos primigenios. Frente a este contexto, se ha querido cuantificar los cambios en el territorio por actividades antrópicas cuantificando las transformaciones del uso del suelo y los impactos sobre el suelo no artificializado. En este sentido, se emplean imágenes satelitales nocturnas y diurnas que nos permiten cuantificar la evolución de los niveles de radiancia y los cambios en los NDVI desde el 2012. Estos dos indicadores nos permiten visualizar de manera clara las trasformaciones en los usos del suelo y los impactos de radiancia sobre el territorio. Se ha corroborado que los impactos vinculados con la expansión de la frontera agrícola y urbana incrementan anualmente sus superficies a tasas que superan los 4,5\% y que las actividades antrópicas se vinculan con las temperaturas más elevadas del territorio propiciando un cambio de las características propias de los ecosistemas selváticos. Estos resultados evidencian la pérdida de bosques tropicales, pero también sugiere impactos sobre los pueblos originarios que habitan estos territorios.

\section{Abstract}

In the last years the pressures on the Amazon have increasingly become visible due to the transformations of the land and alteration of territorial dynamics in areas previously considered remote and only inhabited by indigenous nations. In this context, we evaluate anthropic-based changes by quantifying the transformations of land use and the impacts on non-artificialized areas. Using night and day satellite images, we quantify the evolution of radiance levels and changes in NDVI since 2012. We obtained a visualization of the transformations in land use and the radiance impacts on the territory. In this sense, this study found that the impacts related to the expansion of the agricultural and urban frontier increase their influence areas at rates that exceed 4.5\%/year and that anthropic activities are linked to the highest temperatures in the territory, motivating a change of the characteristics of rainforest ecosystems. These results show the loss of tropical forests, but also suggests impacts on the indigenous inhabitants of these territories. 


\section{Palabras clave}

Landsat, VIIRS, cambio de suelo, NDVI, Amazonía.

\section{Keywords}

Landsat, VIIRS, soil change, NDVI, Amazon.

1.

\section{Introduction}

En el último siglo hemos visto cómo el proceso de dependencia del ser humano hacia la naturaleza ha mutado dando paso a un sistema extractivista poco sustentable que consume gran cantidad de los recursos y deteriora en gran medida la capacidad del medio para restaurarse. Este está vinculado al sistema capitalista extensamente difundido a lo largo del planeta. En este contexto, las empresas transnacionales y los Estados conciben al medio natural como materia prima para integrarla al mercado global. En general estas actividades extractivas son rentables para quienes las promueven, pero generan extensivos e intensos efectos negativos en el entorno y en las comunidades que dependen directamente del medio natural. Entre las principales afecciones que comportan estos procesos se debe mencionar la destrucción de bosques, contaminación de ríos, empobrecimiento de bases materiales que sustenta la existencia de pueblos originarios locales y la pérdida cultural (Silveira et al., 2019)

En el presente estudio nos hemos centrado en el ecosistema más rico del planeta en cuanto a biodiversidad (FAO, 2000), la Amazonía. A lo largo de estos últimos años se ha conocido sobre los impactos de gran escala que se generan sobre este territorio. Entre los principales procesos que afectan de manera directa a la Amazonía se encuentra la expansión de la frontera agrícola, la tala de bosques, la extracción de petróleo y el crecimiento poblacional (Silveira et al., 2019). Todos estos procesos han originado problemas de deforestación, contaminación ambiental, presiones sobre los pueblos originarios, e incluso genocidios contra las comunidades indígenas (Southgate et al., 2009)

Muchas de estas presiones se encuentran vinculadas a procesos impulsados por el Estado, en donde gran parte de los ingresos nacionales se obtienen de la explotación de esta materia prima. De este modo las actividades extractivistas se han vuelto cada vez más intensivas y extensivas. Además, existen otros procesos que han afectado a este territorio, como la reforma agraria en los años 70s. A través de estas políticas se buscaba la integración de la Amazonía con el resto del territorio nacional.

Ante este escenario se ha creído oportuno cuantificar los impactos que las actividades antrópicas producen en estos territorios de gran valor ambiental a través de análisis de un índice de vegetación y de radiancia de luz de zonas antrópicas. Para este estudio específico se ha identificado como ámbito de estudio el norte de la Amazonía ecuatoriana en la cual se concentra una gran diversidad de fenómenos que pueden alterar las condiciones de los ecosistemas propios de la zona.

Para el desarrollo de este análisis se ha considerado el uso de información satelital. Las imágenes provenientes de sensores remotos son tan diversas que nos ofrecen un amplio abanico de información. Así, desde mediados del siglo pasado, 
se han desarrollado varios estudios referentes a la medición, caracterización y análisis de los procesos territoriales en los que se emplean como fuente principal imágenes aéreas y satelitales diurnas. Adicionalmente, en los últimos años se ha observado el empleo de imágenes satelitales nocturnas provenientes de tecnologías más actuales que nos ofrecen una mayor diversidad de análisis (Grover \& Singh, 2015)

Con base a esto, se ha diseñado una metodología que nos permite caracterizar los impactos antrópicos que afectan el territorio amazónico, generando información actualizada. Para este proceso se han empleado imágenes Landsat y Visible Infrared Imaging Radiometer Suite (VIIRS). A través de estas fuentes de información se analiza el impacto sobre el territorio durante el día y la noche, con lo que se configura un análisis integral del mismo. La metodología desarrollada en este estudio nos permite generar información precisa que podría ser empleada por organismos de vigilancia y control para monitorizar las actuaciones antrópicas que generan impacto sobre el medio natural.

\subsection{Impactos antrópicos sobre la Amazonía}

El Ecuador al estar ubicado en la región tropical forma parte de una de las zonas climáticas con mayor extensión de superficie forestal en el planeta. Este tipo de ecosistema aporta grandes beneficios para la conservación de la vida y de la que dependemos directamente por lo cual constituye una parte clave para obtener una adecuada calidad de vida, no solo para los seres humanos sino en general para todo el ecosistema planetario. Según un informe de la Organización de las Naciones Unidades publicado en 2020, a pesar de haber disminuido las tasas de deforestación neta, en todo el mundo se han perdido 178 millones de hectáreas de bosque desde el año 1990. En este escenario, América del Sur ha mantenido las tasas más elevadas de pérdida neta de bosques en los últimos años $(-2,6 \%), y$ únicamente África registra una tasa más elevada de deforestación $(-3,9 \%)$ (FAO, 2020). En el caso ecuatoriano, se ha visto que los bosques amazónicos se encuentran sometidos a procesos antrópicos de gran impacto, entre ellos la presencia de actividades extractivas petroleras, el incremento de la población, la ampliación de la frontera agrícola así como la tala de madera. En general, estas presiones han sido promovidas por políticas del Estado central que buscaba integrar esta región al resto del territorio.

La región amazónica, atravesó un periodo de aislamiento con respecto al resto del territorio lo cual provocó un desarrollo tardío en cuanto al sistema económico, urbano y social que emergían en las otras dos regiones naturales, sierra y costa (Maiguashca, 1994). Por lo tanto, el proceso de transformación de este territorio posee un carácter singular ya que los procesos de conformación de núcleos urbanos han seguido los mismos ritmos de desarrollo de las actividades capitalistas (Bayón, 2019). En el siglo XVI se consolida un proceso de colonización española al norte de la Amazonía debido a la búsqueda del oro (Bayón, 2019; Wilson et al., 2015). En el siglo XIX, con el "boom del caucho" se afianzó el sistema hacendario basado en la esclavización de indígenas, hasta mediados del siglo XX, cuando se produjo la caída del precio del caucho. Luego a partir de los años 60's de ese siglo surge un nuevo modelo territorial guiado por las infraestructuras petroleras y la colonización promovida por el Estado central a través de la reforma agraria y demás políticas que beneficiaban a los agricultores y ganaderos (Gondard \& Mazurek, 2001; Wilson et al., 2015). Este modelo facilitó la expansión del sector maderero y la agricultura debido a la apertura de vías promovida por la actividad petrolera. Sin embargo, no es sino hasta 1972, con el "boom del petróleo" cuando se empieza a extraer esta materia prima de manera extensiva. Desde entonces, este producto se convirtió en la mercancía de mayor importancia en la economía ecuatoriana (Larrea, 2006). Desde esta fecha, según el Banco Centra del Ecuador se pasó de producir 40 millones de barriles de petróleo al año a 200 millones en la segunda década de este siglo. En 1980, a través de políticas públicas se promueve la ampliación de la frontera agrícola, la construcción deinfraestructuras, las concesiones de tierras y la colonización, todo esto con el fin de lograr una articulación de la Amazonía con la estructura económica y urbana del país. Esta búsqueda de integración se encontraba influenciada por el interés de mercados internacionales, de modo que se requería que esta zona se vuelvería más atractiva para las inversiones extranjeras, bajo una lógica de competencia capitalista a escala mundial. 
Adicionalmente, en esta época se gestaba un proceso de democratización y descentración política. Es así que la coyuntura de ese momento influye para que se iniciara esta integración regional (Alexiades \& Peluso, 2016; Carrión, 1994).

Además de las presiones generadas por la presencia de actividades extractivas, la Amazonía ecuatoriana ha visto cómo la expansión de las actividades agrícolas, de pequeñay grandeescala, han consumido ampliamente los bosques tropicales (Southgate et al., 2009; Wunder, 2003). Estos procesos que afectan a los sistemas de bosques son complejos ya que se multiplican en el tiempo y en el espacio generando efectos nocivos en zonas distantes (Silveira et al., 2019). Esto también repercute en el territorio en sí como en los pueblos nativos que dependen del bosque para su subsistencia (Southgate et al., 2009).

En los últimos años la población en la Amazonía se ha incrementado de manera significativa, produciendo intensos procesos de urbanización (Jarrín et al., 2017). Varios pequeños centros poblados se han consolidado como centros dotadores de servicios, generando así un mayor dinamismo económico (Bayón, 2019; Wilson \& Bayón, 2017). Además de los proceso urbanos, los cultivos de palma africana y la actividad maderera dinamizan la economía, pero es difícil cuantificar las aportaciones reales a la economía regional (Bayón, 2019).

Con respecto a la tala ilegal, a pesar de los controles por parte del Estado, esta actividad se sigue desarrollando. Según la ONU, el tráfico de madera ilegal en Latinoamérica ha aumentado y, según sus datos, $30 \%$ de la madera que se comercializa en el mundo es ilícita. En el Ecuador este porcentaje podría ser mayor al 40\%, por lo que el MAE ha intensificado los controles (Coronel, 2018). A través de varios estudios realizados en la zona (Mejia \& Pacheco, 2013; Schlotzhauer \& Torres, 2017) se ha comprobado que la explotación maderera representa una fuente importante de ingresos para los hogares emplazados en este territorio pero también genera graves impactos ambientales, paisajísticos y sociales (Aguirre, 2007). En este sentido, tal y como se encuentran planteadas las políticas y estrategias que rigen el mercado de la madera ecuatoriana, no se garantiza la conservación de los bosques a largo plazo (Southgate et al., 2000).
Por otro lado, es importante resaltar que el país maneja políticas de compensación social como forma de retribución por las afecciones que se generan debido al desarrollo de la actividad petrolera. Entre los proyectos desarrollados sobresalen las Ciudades del Milenio, que fueron la respuesta otorgada por parte del Estado ante intensas manifestaciones por parte de la comunicad local para exigir derechos fundamentales. Sin embargo, estas ciudades han resultado ser modelos urbanos poco sostenibles debido a la falta de trabajo, el precario o inexistente sistema productivo y la inadecuada articulación con los sistemas agrícolas de subsistencia (Wilson et al., 2015). Es importante también mencionar que, en la región, la falta de ingresos alternativos y la pobreza constituyen un aliciente para desboscar las tierras para propósitos agrícolas (FAO, 2000), de modo que parte de la problemática vigente está directamente vinculada con la situación socioeconómica de las personas que habitan estas zonas.

En definitiva, las políticas y procesos influenciados por las sociedades globalizadas y las lógicas capitalistas que rigen en este territorio han provocado profundas transformaciones tal como la destrucción de bosques, la contaminación de ríos, el empobrecimiento de las bases materiales que sustentan la existencia de las comunidades locales, la usurpación de tierras, la pérdida de la cultura y la desaparición de pueblos enteros (Mark Aguirre, 2010; Southgate et al., 2009).

\subsection{Caracterización del ámbito de estudio}

El presente estudio se aplicó en la zona amazónica norte del Ecuador, que abarca principalmente la provincia de Sucumbíos y Orellana, que presenta una gran complejidad. En esta zona se emplazan los bloques más productivos de petróleo y los principales asentamientos humanos de la Amazonía ecuatoriana. Además, es importante mencionar que en esta zona se han identificado 6850 sitios de contaminación por hidrocarburos de los 7850 registrados por el MAE a nivel nacional. 


\section{Figura 1}

Mapa 1. Bloques petroleros en el Ecuador operados por empresas públicas y privadas, 2017.

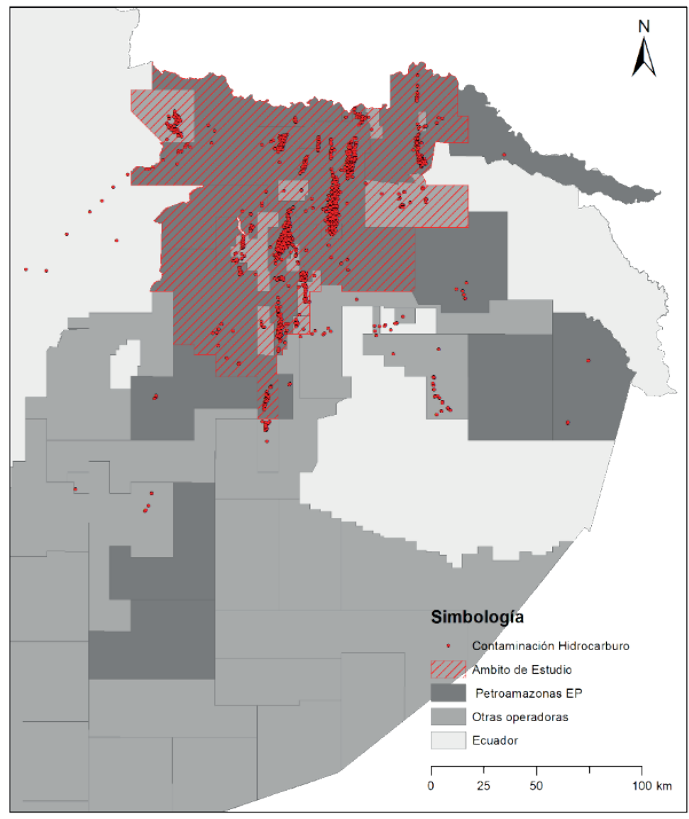

Elaboración: Autores con base en información del Ministerio de Hidrocarburos

Según los datos más actualizados (MAE, 2018) en el territorio continental del Ecuador se pierden alrededor de $600 \mathrm{~km} 2$ de superficie de bosque nativo al año. Considerando la alta biodiversidad del Ecuador es evidente que este fenómeno afecta a un gran número de especies alterando los ciclos fenológicos de los ecosistemas. A pesar de que el ritmo de desaparición de los bosques nativos ha sido menos intensivo en los últimos años, los impactos en términos absolutos siguen siendo importantes. En la Amazonía norte del Ecuador, se observa que en la mayoría de los casos las tasas de deforestación de esta zona sobrepasan las tasas medias nacionales. La tasa de deforestación anual en estos últimos 8 años ha disminuido a menos de la mitad $(-0,67 \%)$ en relación con la década anterior $(-1,73 \%)$. Aun así, a pesar de la ralentización del proceso de deforestación, los ecosistemas que se pierden cada año siguen siendo extensos (Véase Figura 2).

\section{Figura 2}

Mapa 2. Deforestación en el área de estudio, en el marco temporal 1990 a 2018.

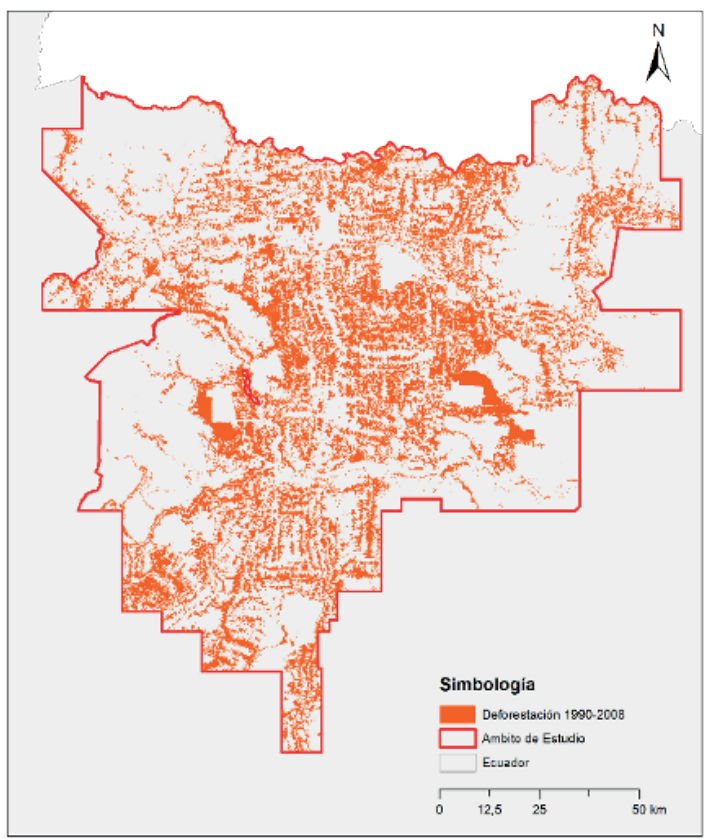

Elaboración: Autores con base en información del MAE

Gran parte de los suelos transformados debido a los procesos de deforestación son empleados para actividades de mayor rentabilidad económica. Así, la superficie antes considerada como bosque nativo pasa a formar parte de las coberturas de tierras agropecuarias, zonas antrópicas e infraestructuras.

En la última década las áreas catalogadas como pobladas, infraestructuras y sin cobertura vegetal registran las máximas tasas medias anuales acumuladas (TMAA), es decir que son las que en términos porcentuales han incrementado de manera más extensiva sus superficies (MAE, 2018). Además, en términos absolutos, se observa que las tierras agropecuarias han incrementado su superficie en una media de $64 \mathrm{~km}^{2}$ por año, entre el 2000 y el 2018, es decir, $1147 \mathrm{~km}^{2}$ en total. En definitiva, a través de estos datos se aprecia que existe una tendencia donde las áreas intervenidas por actividades antrópicas se incrementan a ritmos significativos. 


\section{Tabla 1}

Cambios de cobertura del suelo en el ámbito de estudio con los TMAA, 1990, 2000 y 2018

\begin{tabular}{|l|c|c|c|c|c|}
\hline \multicolumn{1}{|c|}{ Cobertura $\left(\mathbf{k m}^{2}\right)$} & $\mathbf{1 9 9 0}$ & $\mathbf{2 0 0 0}$ & $\mathbf{2 0 1 8}$ & TMAA 1990-2000 & TMAA 2000-2018 \\
\hline Área poblada & 11 & 35 & 98 & $11,6 \%$ & $5,8 \%$ \\
\hline Infraestructura & 1 & 7 & 32 & $29,7 \%$ & $8,4 \%$ \\
\hline Área sin cobertura vegetal & 19 & 11 & 41 & $-4,9 \%$ & $7,4 \%$ \\
\hline Bosque nativo & 12806 & 10756 & 9521 & $-1,7 \%$ & $-0,7 \%$ \\
\hline Tierra agropecuaria & 2059 & 4098 & 5245 & $7,1 \%$ & $1,4 \%$ \\
\hline Natural & 355 & 355 & 331 & $0,0 \%$ & $-0,4 \%$ \\
\hline Vegetación arbustiva & 9 & 36 & 3 & $-9,0 \%$ & $-0,7 \%$ \\
\hline Vegetación herbácea & 112 & 6 & 2 & $-6,2 \%$ & $-5,3 \%$ \\
\hline
\end{tabular}

Elaboración: Autores con base en información del MAE

Como parte de las presiones generadas por las actividades antrópicas se debe considerar el volumen poblacional que acoge esta zona. Si bien es cierto, los asentamientos principales que se identifican en la zona norte de la Amazonía no son precisamente los más extensos del país, en estos últimos años estos han adquirido una mayor connotación para el desarrollo de diversas actividades, por lo cual se consideran importantes focos de atracción demográfica. Según las proyecciones demográficas realizadas a partir de los datos del Censo 2010, se estableció que la población ecuatoriana se incrementaría a una tasa media anual acumulativa de 1,55\%, mientras que para esta zona específica se ha calculado una tasa media anual de 2,14\%. Desde inicio del presente siglo, la población del territorio prácticamente se ha duplicado.

Esta población se distribuye principalmente en cuatro centros poblados. En orden de concentración se encuentra Nueva Loja o Lago Agrio (91744 habitantes), Puerto Francisco de Orellana, también conocido como El Coca (72795), Shushufindi (44328) y La Joya de los Sachas (37561). 


\section{Figura 3}

Mapa 3. Concentración demográfica en el ámbito de estudio

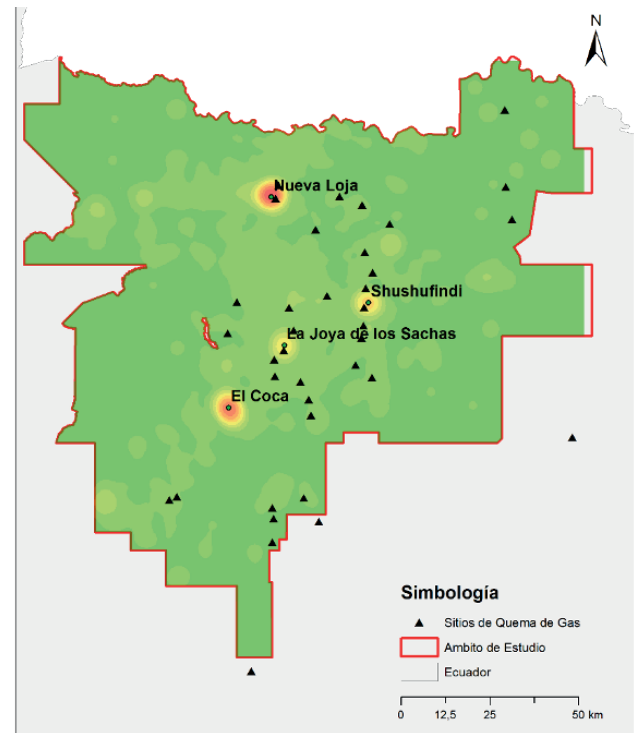

Elaboración: Autores con base en información a los datos de los Censos INEC 2010.

En cuanto a la producción de petróleo se observa que el volumen de extracción ha atravesado por ligeras fluctuaciones en los últimos años. Considerando periodos de 10 años, desde 1990 se ha obtenido que la tasa media anual ha variado de $2,99 \%$ -hasta el 2000, a un 2,17\% entre el 2000 al 2010 y finalmente a un 0,54\% del 2010 al 2018. Es decir, que el ritmo de incremento de la producción de crudo está en descenso, aun así el volumen total refleja un tendencia en aumento.

En el ámbito de estudio se encuentran inmersos los principales bloques petroleros de Petroamazonas, empresa pública del Ecuador encargada de la extracción de petróleo. El bloque 60 - Sacha, 57Shushufindi, 61 - Auca y 43 - ITT son los de mayor producción según los reportes de esta empresa. Estos cuatro bloques contribuyeron con el $65 \%$ de la producción total de los bloques asignados a Petroamazonas durante el año 2018, según los reportes anuales de esta misma empresa. Según estos datos el bloque Sacha es el más rentable y el de mayor producción, mientras que el bloque ITT constituye el mayor proyecto hidrocarburífero del país, por lo que se prevé un incremento sustancial en el volumen de explotación.

El bloque 43-ITT es de reciente incorporación, registra su primer volumen de producción en 2016. Parte de este territorio forma parte del Parque Nacional Yasuní, que en 1989 fue declarado como Reserva de la Biosfera por la UNESCO. En el 2007, el Gobierno ecuatoriano promovió la iniciativa Yasuní ITT, donde se comprometía a la no explotación del petróleo a cambio de una compensación económica por la comunidad internacional bajo un criterio de economía ecológica (Alianza País, 2013; Cabellos, 2010). Sin embargo, la iniciativa no prosperó, y se dio por finalizada en el 2013 empezando así las prospecciones para la explotación.

Frente a este escenario, es importante subrayar los grandes saltos que ha dado el precio del petróleo, desde el 2012, que alcanzó un precio medio de \$95,5, pero descendió a \$35 en el 2016. Estas brechas en los precios influyen de manera directa en los ingresos del país, recursos necesarios para cubrir los proyectos planificados a nivel nacional. La caída de los precios del petróleo afecta al presupuesto general del Estado, puesto que el Ecuador es un país altamente dependiente de los ingresos generados por este producto. La dependencia hacia este recurso hace que las actividades extractivas sigan siendo de gran prioridad para el Estado en detrimento del medio natural en el que se producen. En el ámbito del presente estudio existen una gran cantidad de sitios que han registrado algún tipo de contaminación por hidrocarburos y además en sitios en los que se produce la quema de gases (Elvidge et al., 2016).

A la luz de los resultados presentados se ha observado que son varias las presiones antrópicas que rigen el ámbito de estudio. Considerando las variaciones generadas desde el inicio del presente siglo, se ha calculado que el incremento de la extracción de petróleo que registra actualmente una tasa media anual acumulativa de 1,22\% según datos del Banco Central del Ecuador, la presión demográfica registra una tasa de 3,25\% según las proyecciones del Instituto Nacional de Estadísticas y Censos. En cuanto a las transformaciones del suelo se ha observado que existe una tasa de deforestación anual de 0,67\% (MAE, 2018) en el área de estudio mientras que las áreas vinculadas 
con actividades antrópicas se incrementan a un ritmo mucho más elevado de un 6,3\% anual y las áreas destinadas a la producción agrícola a una tasa de $1,38 \%$. Es decir, el territorio analizado ha atravesado por intensos procesos que han transformado las características de las capas vegetales del suelo.

\section{2.}

\section{Metodología}

A fin de obtener datos sobre las características de las diferentes coberturas identificadas en el territorio se realizó un cruce entre los datos de temperatura provenientes del Landsat 8 y de coberturas de usos de suelo identificadas en la base de datos de SIGTIERRAS. Esta información forma parte de un proyecto emblemático del MAE y el Ministerio de Agricultura, Ganadería, Acuacultura y Pesca (MAGAP) y posee una escala de 1:25000.

En primer lugar, se hará referencia a las características y la metodología empleada para la obtención de los datos de las imágenes satelitales nocturnas VIIRS y luego a las imágenes LANDSAT. Las imágenes satelitales nocturnas empleadas en este estudio forman parte de la serie Versión 1 VIIRS Day/Night Band Nighttime Lights generadas por el National Geophysical Data Center (NGDC) de la Nacional Oceanic and Atmospheric Administration (NOAA). Los valores de las imágenes hacen referencia a unidades de radiancia en nanoWatts $/ \mathrm{cm}^{2} / \mathrm{sr}\left(10^{-9} \mathrm{~W} \cdot \mathrm{cm}^{-2} \cdot \mathrm{Sr}^{-1}\right)$. Tienen una amplia resolución radiométrica correspondiente a 16 bits. Los valores se encuentran en un rango de 7 órdenes de magnitud lo cual evita la saturación de zonas con elevados niveles de radiancia y también detecta bajos niveles de radiancia, por lo que permite analizar valores extremos (Liao et al., 2013).

Para realizar el análisis comparativo se emplearon imágenes anuales del periodo 2012-2019. Las imágenes anuales son el resultado del procesamiento de imágenes mensuales disponibles en el portal del NOAA a través del cual se descartan las observaciones con nubes, se genera un compendio de valores de radiancia y se obtiene la radiancia media del territo- rio representativa del año considerado (Mejía, 2020). Haciendo uso de las imágenes anuales se procede al cálculo del valor de la intensidad radiante y la radiancia media de los diferentes ámbitos de estudio. La intensidad radiante hace referencia a la magnitud de radiancia emitida por una superficie. Para la obtención de este indicador se suma los productos de la relación entre superficie y valores de luminosidad. Mientras que la radiancia media hace referencia al valor promedio de la radiancia para cada ámbito de estudio. Este valor es el cociente entre la radiancia total emitida divida para superficie total del ámbito considerado.

Las imágenes LANDSAT son de gran utilidad para el análisis de la temperatura superficial y la evolución del NDVI (Normalized Difference Vegetation Index). El NDVI es uno de los índices más usados en análisis digital de imágenes satelitales. Este índice es una función de las bandas espectrales del rojo e infrarrojo cercano, usando la siguiente fórmula:

$$
\text { NDVI }=(\text { IRC }- \text { R) } /(\text { IRC }+ \text { R })
$$

En donde IRC es el infrarrojo cercano y R es el rojo. Los valores que puede tener este índice poseen un rango de 0 a 1, en donde los valores más cercanos a 1 sugieren vegetación más frondosa, con mayor biomasa, más producción de clorofila, y más saludable.

Para la determinación de la temperatura se emplearon los datos provenientes de las LANDSAT 8, puesto que poseen bandas que permiten una mayor precisión de este tipo de datos (Ariza, 2013). Para el análisis de NDVI se emplearon datos provenientes del LANDSAT 7 debido a que existen datos disponibles en un mayor rango temporal (1999 a 2020).

Para la obtención de los datos presentados fue necesario realizar una corrección atmosférica de las imágenes, lo cual nos permite estandarizar las comparaciones de datos provenientes de diferentes sensores o fechas. Así, empleando imágenes con corrección topográfica se procedió a realizar las correcciones radiométricas y de reflectancia (Chander et al., 2009). Con las imágenes corregidas se construyeron imágenes anuales a partir de un mínimo de 3 imágenes diarias del año analizado. Las imágenes diarias seleccionadas para este proceso correspondieron a 
las fechas con el mínimo de nubosidad registrada a lo largo del año. Con las imágenes anuales elaboradas se procedió con el cálculo de temperatura y NDVI. Todas las bases de datos empleadas se ajustaron al sistema de coordenadas WGS-1984 proyección UTM zona 17 sur.

Para un análisis más detallado y comparativo se identificaron cuatro áreas o ciudades que delimitan los principales procesos antrópicos del sector (El Coca, La Joya de los Sachas, Nueva Loja y Shushufindi). Para la delimitación de estas áreas se han considerado los centroides de cada asentamiento y se generaron buffers de $10 \mathrm{~km}$ radio. Estas ciudades presentan características más o menos similares dentro del contexto ecuatoriano.

\section{3.}

\section{Resultados: Caracterización del territorio a través de sensores remotos}

Tal como se mencionó en el apartado metodológico, esta investigación emplea dos fuentes básicas para el análisis del paisaje en la Amazonía norte ecuatoriana. En primer lugar, se presenta una caracterización del suelo a través de los niveles de temperatura de las superficies del mismo y de los niveles de radiancia emitidos. Luego se procede a realizar un análisis temporal sobre los cambios registrados por los sensores remotos empleando los valores de radiancia y los datos de NDVI.

\subsection{Caracterización de coberturas naturales por temperatura y por radiancia en el año 2013.}

De acuerdo con los datos obtenidos la mayor parte del área de estudio (94\%) posee una temperatura que oscila entre los 23 y $26{ }^{\circ} \mathrm{C}$, predominando la cobertura de bosque nativo. También se ha podido determinar que las coberturas vinculadas con la actividad antrópica registran valores de temperatura más elevados que la media. En general las coberturas referentes a áreas pobladas registran temperaturas que varían entre 27 y $34^{\circ} \mathrm{C}$, mientras que las coberturas referentes a infraestructura antrópica registran temperaturas más elevadas que llegan hasta el máximo registrado, $36^{\circ} \mathrm{C}$. De este modo se puede inferir que las actividades antrópicas generan impactos en el territorio que incrementan las temperaturas de la superficie. Este fenómeno seguramente se encuentra asociado al material de las edificaciones presentes en las zonas pobladas y áreas de infraestructura antrópica. 


\section{Figura 4}

Caracterización de las coberturas de usos de suelo por temperatura

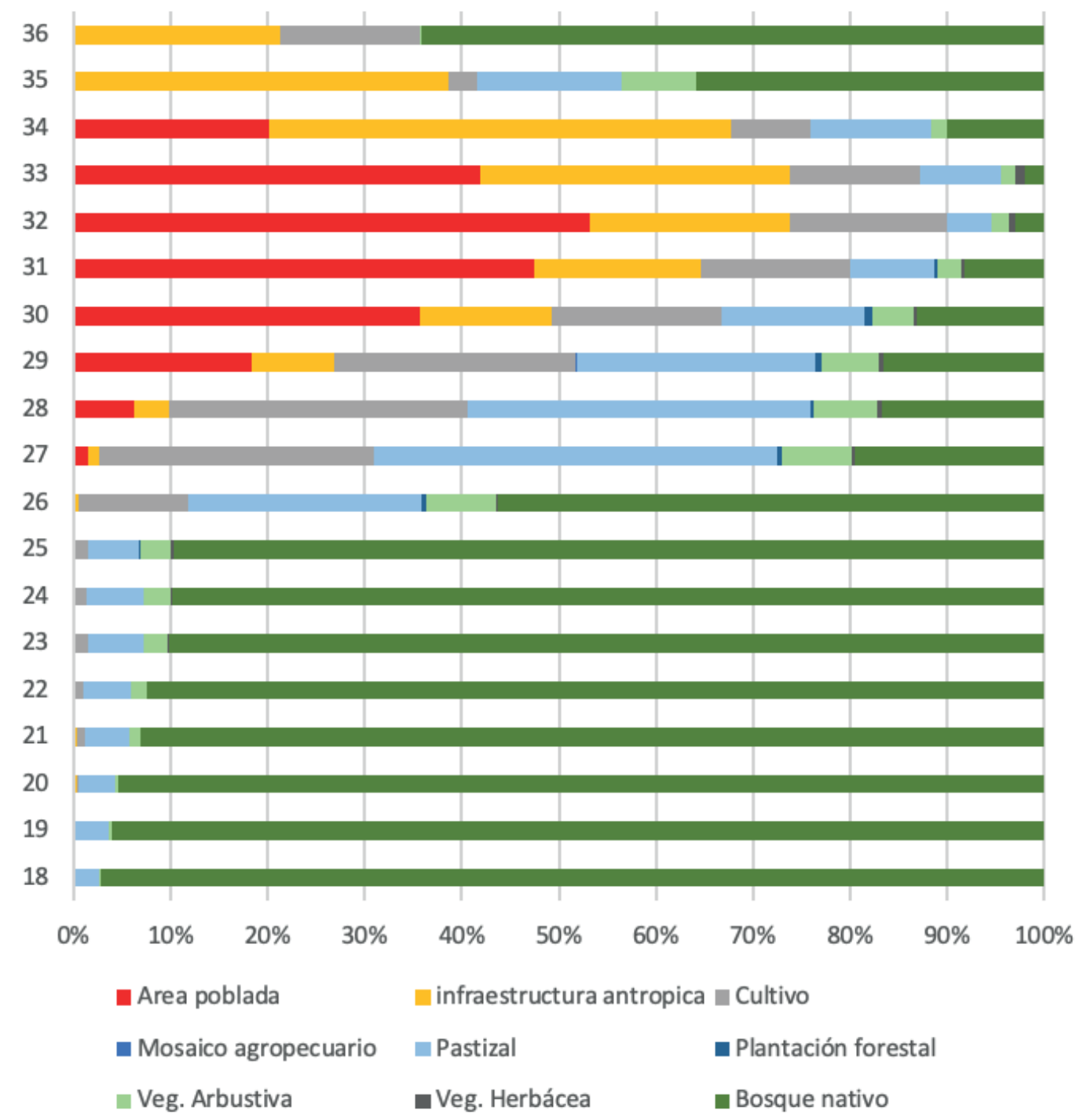

Elaboración: Autores con base en información del LANDSAT8 del año 2013

Por otro lado, al realizar el cruce de información entre las coberturas establecidas por SIGTIERRAS y los valores de radiancia se observa que el $80 \%$ del territorio registra niveles de radiancia bajo los $2 \mathrm{nW} / \mathrm{cm}^{2} /$ sr. El resto del territorio se distribuye en un amplio rango dinámico en el que se observa que las zonas con coberturas urbanas registran niveles de radiancia inferiores a 56, mientras que la infraestructura antrópica registra radiancias superiores. Debido a la naturaleza de los datos analizados, se considera que la luminosidad emitida por focos específicos se dispersa hacia el territorio circundante. Este fenómeno explica que zonas con coberturas boscosas alcancen elevados niveles de radiancia. El grado de dispersión depende del tipo y la intensidad de la fuente emisora. 


\section{Figura 5}

Caracterización de las coberturas de usos de suelo por niveles de radiancia

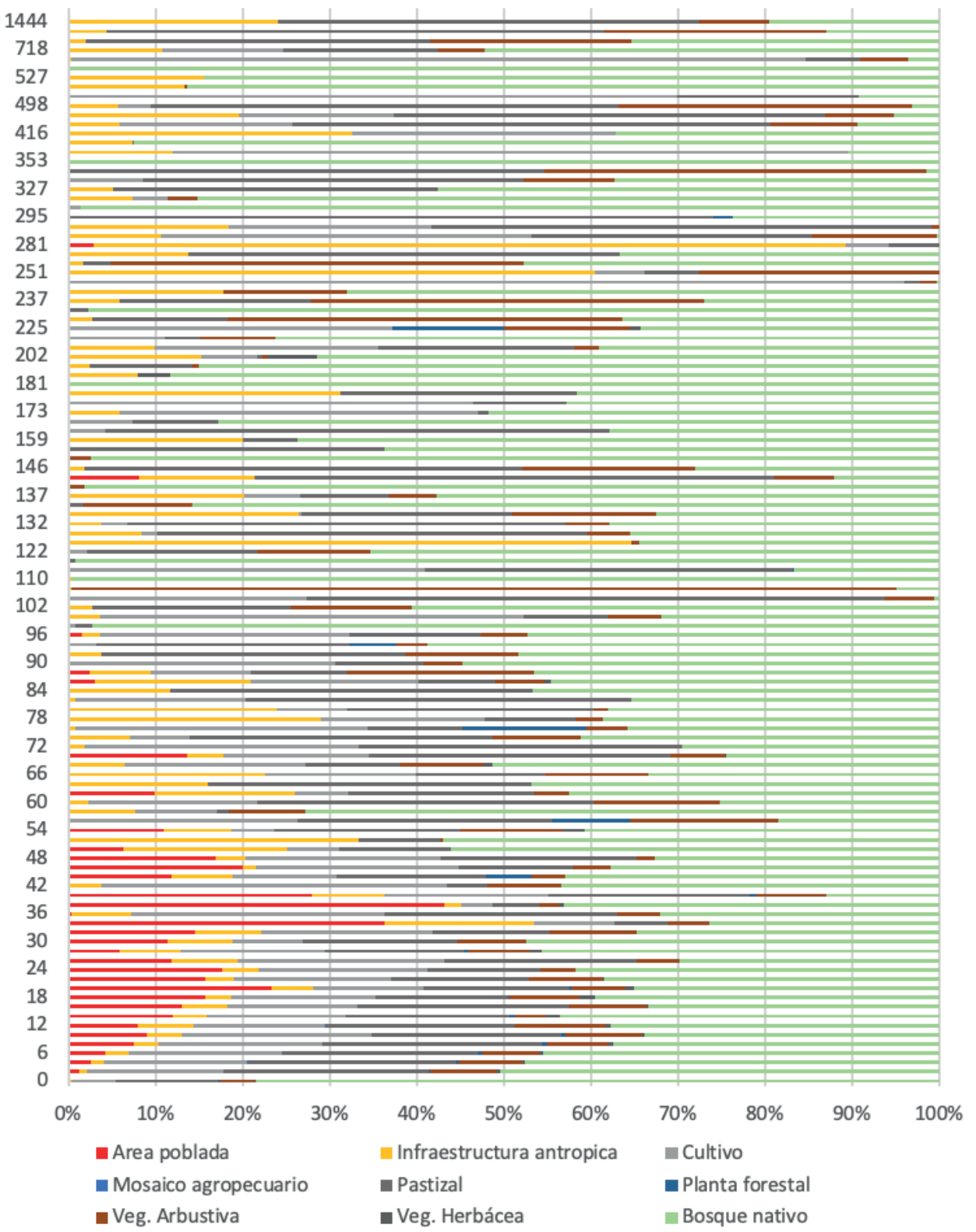

- Mosaico agropecuario

- Veg. Arbustiva
— Veg. Herbácea
- Planta foresta

Bosque nativo

Elaboración: Autores con base en información de las VIIRS año 2013 
En definitiva, las áreas boscosas predominantes en el ámbito de estudio reflejan radiancias inferiores a 2, mientras que para el resto de territorio con intensidades más marcadas se puede inferir que se encuentra por la dispersión de la luminosidad emitida por usos antrópicos tanto de áreas pobladas como de zonas destinadas a infraestructura antrópica.

\subsection{Evolución en los impactos lumínicos en el territorio entre el año 2012 al 2019 .}

A través de un análisis temporal en el que se ha empleado como fuente base las imágenes VIIRS se ha obtenido las variaciones en las emisiones lumínicas del área de estudio entre 2012 y 2019. En base a los resultados se establece que la radiancia se ha incrementado con una tasa media anual de $7,2 \%$, pasando de registrar $132 \mathrm{~kW} /$ sr a $249 \mathrm{~kW} / \mathrm{sr}$.

En conjunto, las cuatro áreas pobladas delimitadas con radios de $10 \mathrm{~km}$, han incrementado su intensidad radiante de 46 a 92 kW/sr entre 2012 y 2019. Es decir, incrementan su intensidad radiante en un 10\% anual. La intensidad radiante emitida por estos asentamientos no se distribuye de manera equitativa. El asentamiento denominado La Joya de los Sachas registra el mayor volumen de intensidad radiante y la tasa de incremento anual más elevada. Se recordará que según el Censo 2010, La Joya de los Sachas y Shushufindi registraban el menor volumen poblacional, sin embargo, concentran los mayores niveles de emisión radiante. En este sentido, resulta lógico suponer que estas emisiones lumínicas se encuentran vinculadas principalmente a usos distintos a lo típicamente urbano. En este sentido, próximos a estos asentamientos se localizan sitios de extracción que generalmente son los que producen la quema de gas que son los focos de las emisiones de radiancia.

\section{Figura 6}

Evolución de la intensidad radiante en los principales centros urbanos del Área de Estudio, 2012- 2019

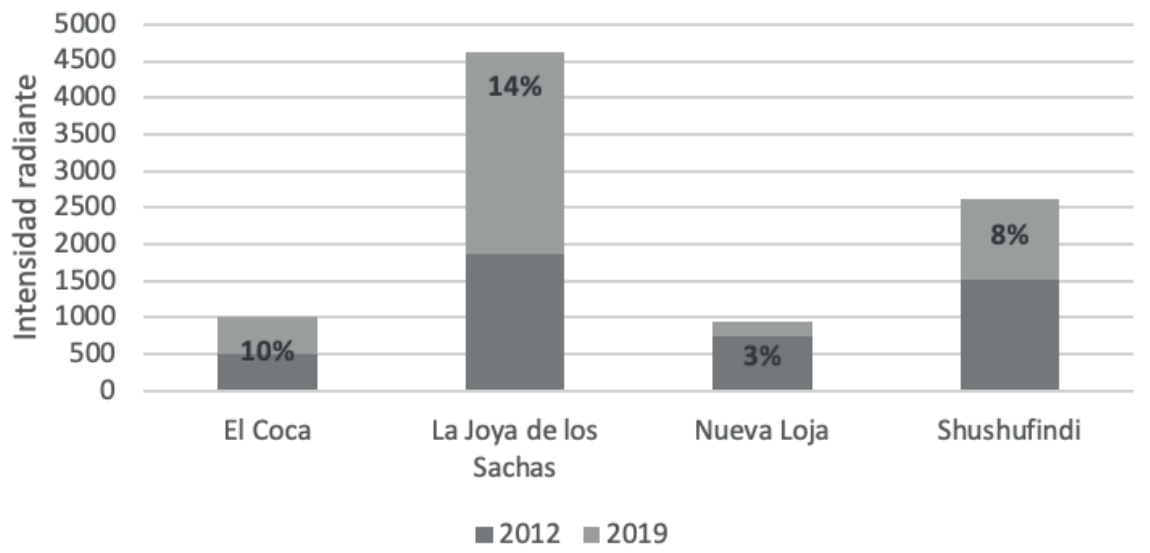

Elaboración: Autores con base en información VIIRS

\subsection{Evolución de las coberturas vegetales en zonas con mayor impacto antrópico}

Para este análisis se ha considerado como ámbito de estudio las cuatro ciudades mencionadas anteriormente, que son los lugares en donde se concentran las principales actividades antrópicas de la zona, y a la vez coinciden con áreas que no se encuentran afectadas por nubosidad. Haciendo uso de los datos extraídos de las imágenes Landsat se ha realizado una categorización de los valores referentes al NDVI. Basándonos en 
varios estudios (Chuvieco Salinero, 1998; Stefanov et al., 2001; Stefanov \& Netzband, 2005) y corroborando a través de un contraste de los valores de NDVI de las imágenes satelitales y las coberturas de usos de suelo de SIGTIERRAS, se realizó una clasificación en cinco rangos que permiten distinguir los distintos tipos de suelo en base a las características de mapas de coberturas, imágenes satelitales diurnas.

\section{Tabla 2}

\section{Clasificación NDVI}

\begin{tabular}{|l|c|l|l|}
\hline CATEGORÍA & RANGO & \multicolumn{1}{|c|}{ TIPO } & \multicolumn{1}{c|}{ DESCRIPCIÓN } \\
\hline 1 & $-\mathrm{n}-0,2$ & $\begin{array}{l}\text { Sin vegetación, agua, } \\
\text { sombras }\end{array}$ & $\begin{array}{l}\text { Gran parte de estos suelos corresponden prin- } \\
\text { cipalmente a zonas oscuras y vinculadas a ríos }\end{array}$ \\
\hline 2 & $\begin{array}{c}0,2- \\
0,45\end{array}$ & $\begin{array}{l}\text { Suelo sin cobertura o } \\
\text { escasa vegetación }\end{array}$ & $\begin{array}{l}\text { Se ha visto que esto suelo coincide con las áreas } \\
\text { urbanas }\end{array}$ \\
\hline 3 & $\begin{array}{c}0,45- \\
0,55\end{array}$ & Vegetación escasa & $\begin{array}{l}\text { Gran parte de estos suelos corresponden a sue- } \\
\text { los en procesos de transformación, pastizales }\end{array}$ \\
\hline 4 & $\begin{array}{c}0,55^{-} \\
0,65\end{array}$ & Vegetación dispersa & $\begin{array}{l}\text { Suelos vinculados con actividades agrícolas y } \\
\text { vegetación arbustiva y herbácea }\end{array}$ \\
\hline 5 & $0,65-1$ & Bosque & Suelo con abundante vegetación arbustiva \\
\hline
\end{tabular}

En el conjunto de los cuatro asentamientos se ha visto como el NDVI ha variado de manera significativa en estas última dos décadas. Tal como era de esperarse el rango que abarca principalmente áreas urbanas se ha incrementado de manera exponencial, al igual que las zonas vinculadas con vegetación dispersa, en donde se han observado cubiertas vinculadas con actividades agrícolas, vegetación arbustiva y herbácea. Estas dos categorías 2 y 4 mantienen las TMAA más elevadas. Mientras que las áreas boscosas se reducen de manera más significativa en términos absolutos. El NDVI 5 se ha reducido en $159 \mathrm{~km}^{2}$ en 18 años.

\section{Tabla 3}

Evolución de las superficies por NDVI entre los años 2001-2019

\begin{tabular}{|l|c|l|l|c|l|}
\hline NDVI & $\mathbf{2 0 0 1}$ & $\mathbf{2 0 1 9}$ & DIFERENCIA (KM2) & \% & \multicolumn{1}{|c|}{ TMAA } \\
\hline 1 & 20,9 & 15,7 & $-5,2$ & $75 \%$ & $-1,5 \%$ \\
\hline 2 & 21,7 & 50,0 & 28,3 & $231 \%$ & $4,5 \%$ \\
\hline 3 & 10,0 & 8,9 & $-1,1$ & $89 \%$ & $-0,6 \%$ \\
\hline 4 & 89,8 & 226,4 & 136,6 & $252 \%$ & $5,0 \%$ \\
\hline 5 & 1115,2 & 956,5 & $-158,7$ & $86 \%$ & $-0,8 \%$ \\
\hline
\end{tabular}

Elaboración: Autores con base en información Landsat 7

Esta clasificación ha permitido cuantificar los cambios en las cubiertas de suelo en donde la tendencia general muestra una clara expansión de las áreas urbanas y la pérdida de áreas con abundante vegetación, propia de bosques nativos. 
Analizando la transformación de las coberturas del suelo por asentamientos sobresale la Joya de los Sachas. En la categoría 2, a pesar de no ser muy extensa, registra la tasa de variación más elevada (8\%), mientras que a la categoría 5 con una tasa de variación de -1\%, le corresponden una disminución en su extensión de 43,6 $\mathrm{km}^{2}$.

Por otro lado, se ha visto que el asentamiento con menores transformaciones en términos relativos ha sido Nueva Loja. En todas las categorías de NDVI las TMAA se encuentran en un rango de 3\% y $-1 \%$. Así a pesar de que el área urbana se ha expandido y las áreas boscosas se han reducido, lo han hecho a ritmos más lentos que en el resto de asentamientos analizados.

\section{Tabla 4}

Evolución de las superficies por NDVI en los principales centros urbanos del Ámbito de Estudio, 2001-2019

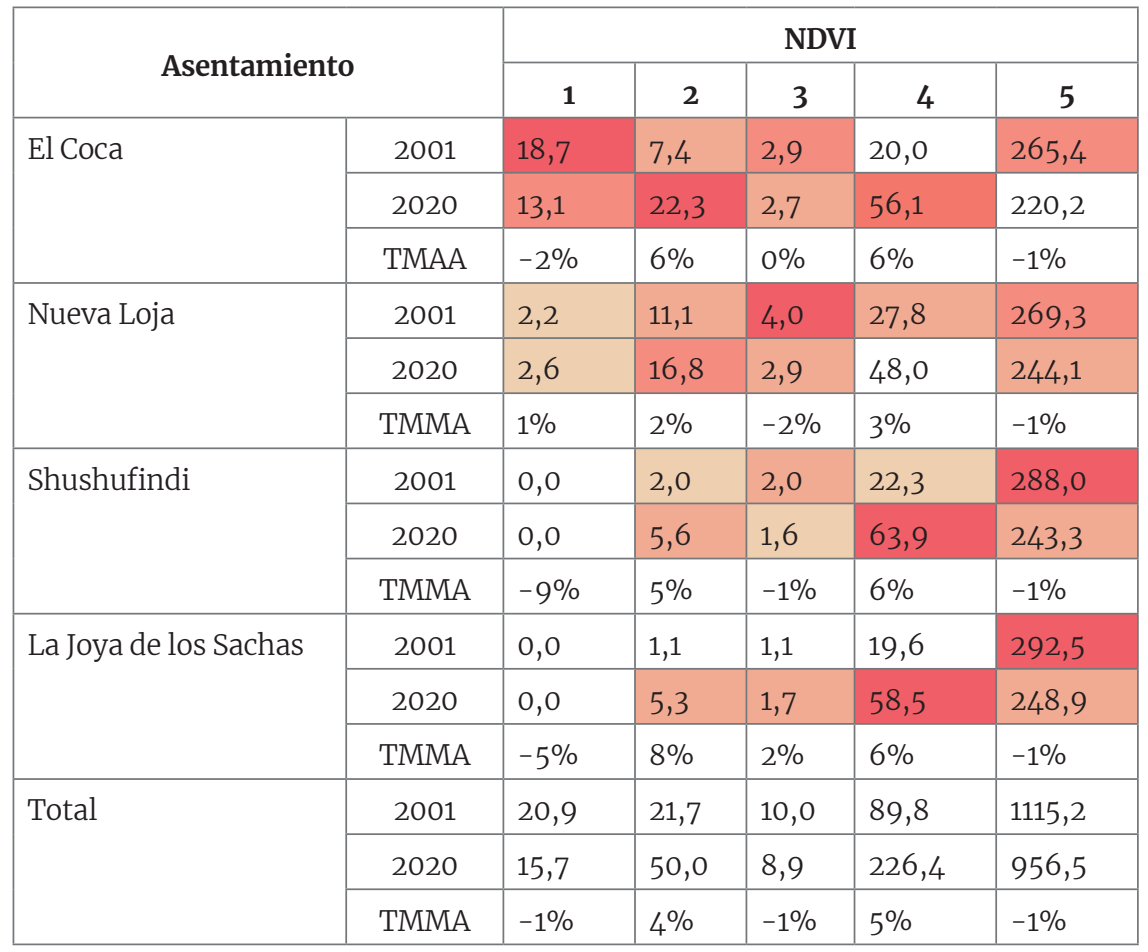

Elaboración: Autores con base en información Landsat 7

En definitiva, todas estas ciudades amazónicas dentro de sus ámbitos de estudio presentan grandes extensiones de bosque que se han visto reducidas a través de los años, mientras que los NDVI relativas a áreas urbanas y áreas con vegetación dispersa se expanden a ritmos considerables. 


\section{Figura 7}

Clasificación NDVI para los años 2000 y junto a este para el año 2020 de los asentamientos de la Amazonía norte del Ecuador.
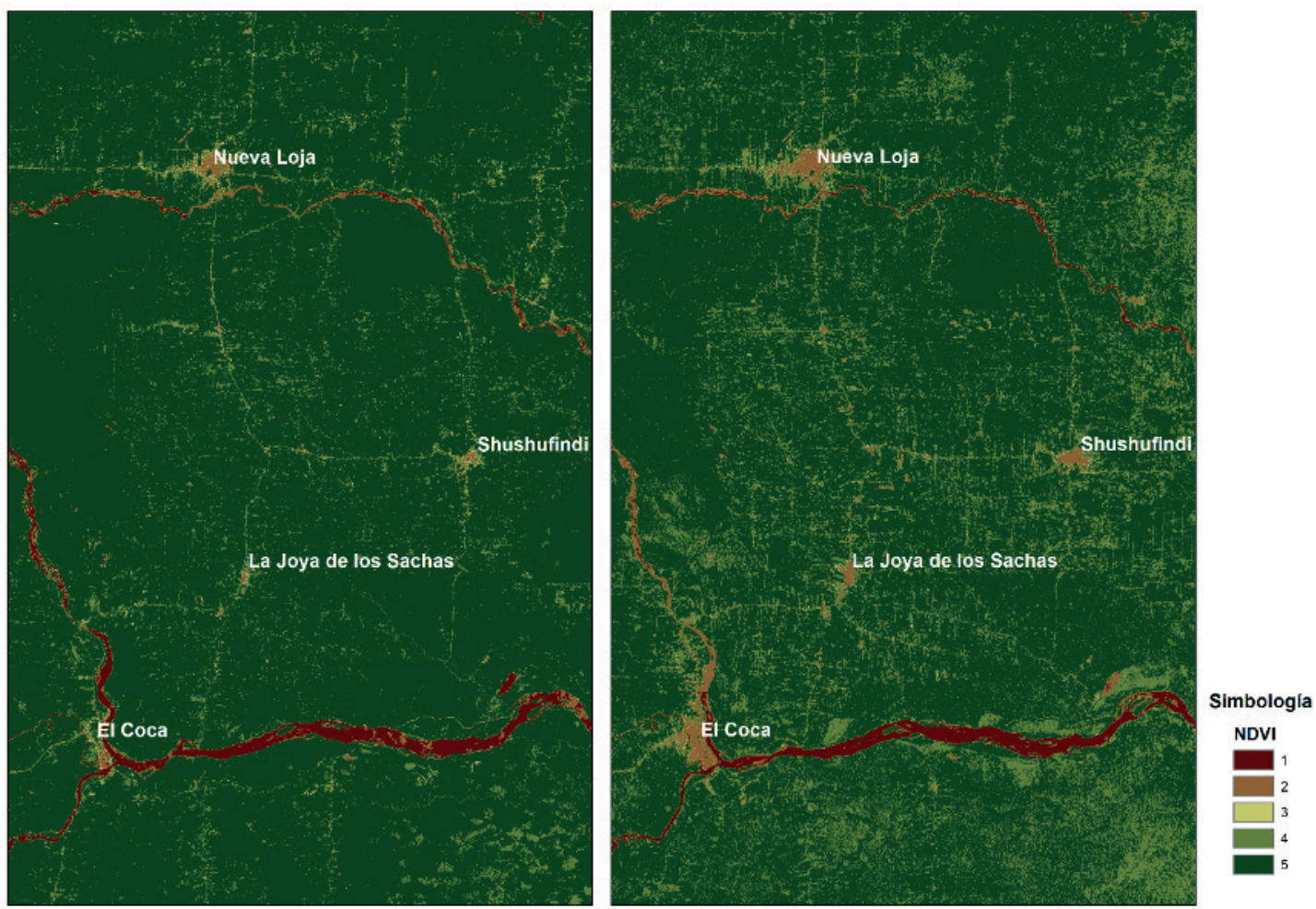

Elaboración: Autores con base en información Landsat 7

4.

\section{Discusión}

En el análisis se ha podido observar que tanto los niveles de radiancia como los cambios en los NDVI reflejan un incremento de las actividades antrópicas en la zona. De este modo, se puede hablar de una tendencia a través de la cual se ha consolidado un continuo proceso de transformación del territorio, debido a las presiones sobre el medio natural.

Adicionalmente se ha podido corroborar que, a diferencia de territorios con características típicamente urbanas donde la emisión de radiancia se encuentra ligada al volumen poblacional, en nuestro ámbito de estudio la contaminación lumínica se vincula a otro tipo de fenómenos. Al observar los datos extraídos del asentamiento 
La Joya de los Sachas, se observa que este registra la mayor intensidad radiante, las mayores tasas de incremento lumínico, y las mayores variaciones en las NDVI 2 y 4, al mismo tiempo que registra el menor volumen poblacional. En ese sentido, se puede inferir que el territorio ha atravesado por profundas transformaciones que están vinculadas a usos distintos a los típicamente urbanos. Por ejemplo, se ha encontrado que tienen relación con la deforestación en la Amazonía norte variables socio-espaciales a escala de finca, como tamaño del hogar, distancia a las ciudades, nivel de educación y estado laboral (Mena et al., 2006). Los elevados niveles de emisiones lumínicas son generados en este caso por actividades extractivistas, específicamente puntos de quemas de gas, y los cambios en los NDVI 2 y 4 corroboran que el territorio se encuentra en un intenso proceso de transformación por fenómenos antrópicos.

Por otro lado, se ha observado que la ciudad de Nueva Loja (Lago Agrio) alberga un mayor volumen poblacional, pero registra las menores tasas de variación en cuanto a intensidad radiante y NDVI. Por lo tanto, resulta razonable suponer que este asentamiento ha atravesado por un proceso menos intensivo que la Joya de los Sachas. En ese sentido, en un estudio reciente realizado por Cabrera-Barona et al. (2020), se encontró que Joya de los Sachas forma parte de una "región urbana amazónica" diferente a Lago Agrio, en términos de diversas variables como número de vías pavimentadas, dimensión fractal, luminosidad (W/rs), y distancias a áreas deforestadas y de contaminación petrolera que al parecer se encuentra en proceso de consolidación y no de expansión (Cabrera-Barona et al., 2020). Los análisis de NDVI y radiancia podrían ser usados como apoyo para evaluar impactos de cambios locales ecosistémicos y climáticos de la Amazonía. Por ejemplo, algunos análisis que consideran los NDVI han demostrado la capacidad de los bosques amazónicos como sumideros de carbono, especialmente durante épocas lluviosas (Potter et al., 2001). La influencia antrópica visualizada a través de la luminosidad muestra como la Amazonía norte del Ecuador es un territorio moldeado por la explotación de recursos asociada con el desarrollo urbano. De hecho, se puede decir que el crecimiento urbano puede ser un síntoma de procesos de extracción de recursos, como la madera o el petróleo. En ese sentido, coincidimos con lo que mencionan (Richards \& VanWey, 2015) al decir que el crecimiento urbano es un síntoma del sistema internacional de producción de mercancías, que son obtenidas a través de recursos que adquieren valor a partir de los mismos residentes urbanos locales. En este contexto, el decrecimiento de valores de NDVI alrededor de las ciudades de nuestro ámbito de estudio, como también al incremento de la luminosidad alrededor de ellas, también muestran interacciones entre las fronteras urbanas y rurales. Lo interesante recae en que, se puede apreciar un avance de lo urbano, en donde se puede decir que el territorio dejaría de ser interpretado a través de la frontera agraria, y más bien, podría ser visto como un sistema entendido en clave de frontera urbana (Simmons et al., 2002).

\section{5.}

\section{Conclusiones}

La información generada a través de la metodología aplicada permitió cuantificar las trasformaciones del suelo aportando a información clave para la caracterización de este territorio. Sin embargo, para comprender el origen de esta situación ha sido necesario identificar el proceso histórico que ha regido en la región y a través del cual se ha configurado el modelo territorial instaurado. En este caso, ha sido evidente cómo las políticas promovidas por el Estado central desde hace varias décadas han generado un proceso de transformación de la región selvática ecuatoriana. Es así como estas políticas han configurado el modelo territorial actual, en el cual confluye una gran diversidad de intereses sobre todo de corrientes capitalistas que escasamente consideran el valor ambiental, social y cultural que existen en esta región, y han intervenido en el territorio bajo el mito del vacío demográfico. Frente a este escenario, la Amazonía ha visto cómo se han impuesto y mantenido dinámicas de suelo que interfieren con los modelos de vida de los pueblos primigenios que dependen de ella para su subsistencia y que dotan al territorio de una gran diversidad cultural.

En este sentido, a través de los datos presentados se ha podido constatar que el territorio analizado conoció profundas e intensivas transformaciones que ini- 
ciaron en el siglo pasado, las cuales continúan hasta la actualidad con ritmos que se han ralentizado en los últimos años. Haciendo uso de las imágenes satelitales se pudo corroborar que los suelos urbanos y las infraestructuras petroleras registran mayores temperaturas y emiten mayores niveles de radiancia que la media del territorio en general. Así las áreas pobladas registran temperaturas entre 27 y $34^{\circ} \mathrm{C}$, mientras que las infraestructuras vinculadas con a la actividad petrolera registran temperaturas de $36^{\circ} \mathrm{C}$. Por su parte al analizar las imágenes Landsat se corroboró que se ha reducido $159 \mathrm{~km} 2$ vegetación arbustiva, y a su vez las zonas con escasa vegetación y vegetación dispersa han incrementado. Además de estas comparaciones generales las imágenes satelitales nos permiten territorializar las zonas que han sufrido cambios, por lo que resulta sencillo identificar y cuantificar estas transformaciones. Así, el análisis desarrollado pretende presentar la utilidad de las fuentes para llevar a cabo estudios territoriales. Haciendo uso de estas fuentes es posible obtener datos actualizados y construir una lectura real del territorio.

\section{Referencias}

Aguirre, Mark. (2010). ¿Golpe de timón en Ecuador? En El Viejo topo (Número 270). Iniciativas Editoriales.

Aguirre, Milagros. (2007). jA quién le importan esas vidas! : un reportaje sobre la tala ilegal en el Parque Nacional Yasuní. Cicame.

Alexiades, M., \& Peluso, D. (2016). La urbanización indígena en la Amazonia. Un nuevo contexto de articulación social y territorial. Gazeta de Antropologia, 32(1).

Ariza, A. (2013). Descripción y corrección de productos landsat 8 LDCM. https://doi.org/10.13140/RG.2.2.21308.44167
Bayón, M. (2019). Una mirada de la Amazonía a través de la urbanización. En Geografía Crítica para detener el despojo de los territorios (pp. 191205). Abya-Yala.

Cabrera-Barona, P. F., Bayón, M., Durán, G., Bonilla, A., \& Mejía, V. (2020). Generating and Mapping Amazonian Urban Regions Using a Geospatial Approach. ISPRS International Journal of GeoInformation, 9(7), 453.

https://doi.org/10.3390/ijgig070453

Carrión, F. (1994). Las ciudades intermedias en el contexto de la urbanización ecuatoriana: un intento de interpretación. Revista Interamericana de Planificación, XVIII, 19.

https://doi.org/10.1017/CBO9781107415324.004

Chander, G., Markham, B., \& Helder, D. (2009). Summary of Current Radiometric Calibration Coefficients for Landsat MSS, TM, ETM+, and EO-1 ALI Sensors. Remote Sensing of Environment, 113(2009), 893.

Chuvieco Salinero, E. (1998). El factor temporal en teledetección: evolución fenomenológica y análisis de cambios. Revista de teledetección: Revista de la Asociación Española de Teledetección, 10,4 .

Coronel,J.(2018).40\% demaderavendidaenEcuador tiene un origen ilegal. El Universo. https:// www.eluniverso.com/noticias/2018/12/02/ nota/7076118/40-madera-vendida-tieneorigen-ilegal-ecuador

Elvidge, C., Zhizhin, M., Baugh, K., Hsu, F. C., \& Ghosh, T. (2016). Methods for global survey of natural gas flaring from visible infrared imaging radiometer suite data. Energies, 9(1). https://doi.org/10.3390/en9010014

FAO. (2000). The Global Forest Resources Assessment 2000. http://www.fao.org/forest-resourcesassessment/past-assessments/fra-2000/es/

FAO. (2020). Evaluación de los recursos forestales mundiales 2020. En Evaluación de los recursos forestales mundiales 2020 . https://doi.org/10.4060/ca8753es 
Gondard, P., \& Mazurek, H. (2001). 30 anos de reforma agraria y colonizacion en el Ecuador : 1964-1994: dinamicas espaciales. Estudios de Geografia, 10, 15-40.

Grover, A., \& Singh, R. (2015). Analysis of Urban Heat Island (UHI) in Relation to Normalized Difference Vegetation Index (NDVI): A Comparative Study of Delhi and Mumbai. Environments, 2(4), 125-138.

https://doi.org/10.3390/environments2020125

Jarrín-V., P., Tapia, L., \& Zamora, G. (2017). Demografía y transformación territorial: medio siglo de cambio en la región amazónica de Ecuador/ Demography and territorial transformation: half a century of change in the Amazonian Region of Ecuador. Eutopía, Revista de Desarrollo Económico Territorial, 12, 81. https://doi.org/10.17141/eutopia.12.2017.2913

Larrea, C. (2006). Petróleo y estrategias de desarrollo en el Ecuador: 1972-2005. En G. Fontaine (Ed.), Petróleo y desarrollo sostenible en el Ecuador: Las ganancias y pérdidas (pp. 57-68). Flacso.

Liao, L. B., Weiss, S., Mills, S., \& Hauss, B. (2013). Suomi NPP VIIRS day-night band on-orbit performance. Journal of Geophysical Research Atmospheres, 118(22), 12705-12718. https://doi.org/10.1002/2013JD020475

Maiguashca, J. (1994). El proceso de integración nacional en el Ecuador. En J. Maiguashca (Ed.), Historia y región en el Ecuador: 1830-1930 (pp. 1830-1930). Corporación Editora Nacional.

Mejia, E., \& Pacheco, P. (2013). Aprovechamiento forestal y mercados de la madera en la Amazonía Ecuatoriana. En Aprovechamiento forestal y mercados de la madera en la Amazonía Ecuatoriana. Documentos Ocasionales 97, CIFOR.

Mejía, V. (2020). Morfología urbana y proceso de urbanización en Ecuador a través de la imagen satelital nocturna de la Tierra , 1992-2012. EURE, 46, 191-214.
Mena, C. F., Bilsborrow, R. E., \& McClain, M. E. (2006). Socioeconomic Drivers of Deforestation in the Northern Ecuadorian Amazon. Environmental Management, 37(6), 802-815.

Potter, C., Klooster, S., de Carvalho, C. R., Genovese, V. B., Torregrosa, A., Dungan, J., Bobo, M., \& Coughlan, J. (2001). Modeling seasonal and interannual variability in ecosystem carbon cycling for the Brazilian Amazon region. Journal of Geophysical Research: Atmospheres, 106(D10), 10423-10446.

https://doi.org/10.1029/2000JD900563

Richards, P., \& VanWey, L. (2015). Where Deforestation Leads to Urbanization: How Resource Extraction Is Leading to Urban Growth in the Brazilian Amazon. Annals of the Association of American Geographers, 105(4), 806-823.

https://doi.org/10.1080/00045608.2015.1052337

Schlotzhauer, P., \& Torres, B. (2017). Análisis de la cadena de producción y comercialización de madera en pequeños productores de la Amazonía Ecuatoriana. March.

Silveira, M., Bayón, M., \& Moreano, M. (2019). Resistencia multiescalar en el Yasuní: Aportes desde la geografía crítica. En Geografía Crítica para detener el despojo de los territorios (pp.103115). Abya Yala.

Simmons, C., Perz, S., Pedlowski, M., \& Silva, L. G. T. (2002). The changing dynamics of land conflict in the Brazilian Amazon: The rural-urban complex and its environmental implications. Urban Ecosystems, 6(1/2), 99-121. https://doi.org/10.1023/A:1025918730400

Southgate, D., Salazar-Canelos, P., Camacho-Saa, C., \& Stewart, R. (2000). Markets, institutions, and forestry: The consequences of timber trade liberalization in Ecuador. World Development, 28(11), 2005-2012.

https://doi.org/10.1016/S0305750X(00)00064-4 
Southgate, D., Wasserstrom, R., \& Reider, S. (2009). Oil Development, Deforestation, and Indigenous Populations in the Ecuadorian Amazon. Latin American Studies Association in Rio de Janeiro, 77098(June 2009), 11-14.

Stefanov, W. L., \& Netzband, M. (2005). Assessment of ASTER land cover and MODIS NDVI data at multiple scales for ecological characterization of an arid urban center. Remote Sensing of Environment, 99(1-2), 31-43.

https://doi.org/10.1016/j.rse.2005.04.024

Stefanov, W. L., Ramsey, M. S., \& Christensen, P. R. (2001). Monitoring urban land cover change: An expert system approach to land cover classification of semiarid to arid urban centers. Remote Sensing of Environment, 77(2), 173-185. https://doi.org/10.1016/S0034-4257(01)00204$\underline{8}$

Wilson, J., \& Bayón, M. (2017). La selva de los elefantes blancos: megaproyectos y extractivismos en la Amazonía ecuatoriana. Abya Yala.

Wilson, J., Bayón, M., \& Diez, H. (2015). Posneoliberalismo y urbanización planetaria en la Amazonía ecuatoriana. Revista Economía, 67, 29-58.

Wunder, S. (2003). Oil wealth and the fate of tropical rainforests: a comparative study of eight tropical countries. Routledge. 